\title{
CONSTRUÇÃO DE UM CORPUS DE ESCRITA INFANTIL COM ITENS DE AVALIAÇÕES
}

GLADYS ROCHA, RAQUEL FONTES MARTINS

\section{RESUMO}

Este trabalho trata de uma pesquisa que propõe a construção de um corpus de escrita infantil, composto de dados da Avaliação Diagnóstica da Alfabetização no Estado do Espírito Santo - Paebes Alfa. Trata-se de uma avaliação sistêmica e em larga escala, na área de alfabetização, leitura e escrita, de caráter longitudinal, aplicada a alunos dos três primeiros anos do ensino fundamental, em duas edições por ano (avaliações de Entrada e Saída), ao longo do período de 2008-2011. Os dados que comporão o corpus citado se referem às aplicações de 2010 e 2011. Também, esses dados são relativos a quatro tipos de itens de escrita do Paebes Alfa, os quais focalizam habilidades de uso da página; escrita de palavras; escrita de frases; escrita de textos. Essa pesquisa pretende contribuir, de forma significativa, para a compreensão do papel de itens de escrita em avaliações externas à escola, bem como para um maior entendimento sobre o processo de aquisição da escrita. Por meio da construção do corpus, poderão ser investigados aspectos dessa aquisição, como os percursos empreendidos pelos alunos em relação à escrita de palavras e o domínio de habilidades de uso da página. 


\section{RESUMEN}

Este trabajo trata de una investigación que propone la construcción de un corpus de escritura infantil, compuesto por datos de la Evaluación Diagnóstica de la Alfabetización en elEstadodeEspíritoSanto-PaebesAlfa.Setratadeunaevaluación sistémica a gran escala, de la evaluación en el área de alfabetización, lectura y escritura, de carácter longitudinal, aplicada a alumnos de los tres primeros años de la enseñanza fundamental, en dos ediciones por año (evaluaciones de entrada y de salida), durante el período 2008-2011. Los datos que compondrán el corpus citado se refieren a las aplicaciones de 2010 y 2011. Estos datos son relativos a cuatro tipos de items de escritura del Paebes Alfa, los que focalizan habilidades en el uso de la página, en la escritura de palabras, de frases y de textos. Esta investigación pretende contribuir de forma significativa a la comprensión del papel de items de escritura en evaluaciones externas a la escuela, así como a un mayor entendimiento sobre el proceso de adquisición de la escritura. Por medio de la construcción del corpus, se podrán investigar aspectos de esa adquisición, como los trayectos recorridos por los alumnos con relación a la escritura de palabras y al dominio de habilidades en el uso de la página.

PALABRAS CLAVE: EVALUACIÓN DEL APRENDIZAJE •

ALFABETIZACIÓN・ESCRITURA・PAEBES ALFA.

\section{ABSTRACT}

This study reports on a survey that proposes the construction of a corpus of children's writing, composed of data from the Literacy Diagnostic Evaluation in the State of Espirito Santo - Paebes Alpha. This is a systematic large-scale assessment in the area of literacy, reading and writing, with a longitudinal perspective, applied to students of the first three years of Elementary School twice a year (Input and Output assessments), over the period 2008-2011. The data that will constitute the corpus refer to the 2010 and 2011 applications. These data are related to four types of writing items in Paebes Alpha, which focus on skills of using the page, writing words, writing sentences, and writing texts. This study aims to contribute significantly to the understanding of the role of written items in evaluations outside the school, as well as to a greater understanding of the writing acquisition process. By constructing the corpus, it will be possible to investigate aspects of this acquisition, such as the paths taken by students in relation to the writing of words and the mastery of skills to use the page.

KEYWORDS: EVALUATION OF LEARNING • LITERACY •

WRITING - PAEBES ALFA. 
1 Agradecemos ao Ministério da Educação - MEC/Instituto Nacional de Estudos e Pesquisas Educacionais Anísio Teixeira - Inep o financiamento para a pesquisa citada que é desenvolvida no Centro de Alfabetização, Leitura e Escrita da Faculdade de Educação da Universidade Federal de Minas Gerais Ceale/FaE/UFMG

\section{INTRODUÇÃO}

Este trabalho trata da pesquisa "Meta-avaliação da alfabetização: uma investigação do papel e potencialidade de itens e escalas de

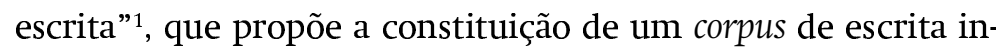
fantil, composto de dados de uma avaliação em larga escala, na área de alfabetização, leitura e escrita: a Avaliação Diagnóstica da Alfabetização no Estado do Espírito Santo - Paebes Alfa.

A fim de abordar esse tema, na próxima seção, são discutidos alguns momentos importantes da avaliação externa à escola no Brasil, com o objetivo de situar o contexto maior de onde os dados da pesquisa se originam. A seção 3 reflete sobre a avaliação da alfabetização, leitura e escrita em nosso país, ressaltando questões que motivaram o desenvolvimento da pesquisa aqui focalizada. A seção 4 trata da pesquisa citada, apontando que sua principal ação é a constituição de um corpus de escrita infantil. A seção 5 apresenta resultados de uma análise preliminar de dados de avaliações do Paebes Alfa. A seção 6 aborda os principais aspectos metodológicos envolvidos na pesquisa. A última seção faz as considerações finais deste trabalho. 


\section{AVALIAÇÃO EXTERNA À ESCOLA NO BRASIL}

Pode-se afirmar que a implementação de avaliações externas à escola como política pública, tal como conhecida hoje, começou no Brasil, na década de 80, quando o Ministério da Educação - MEC iniciou estudos sobre avaliação educacional. Contudo, nesse período, as avaliações focalizavam projetos isolados que, em função de suas particularidades, não permitiam uma integração entre instrumentos ou metodologias de avaliação.

Naquele momento, marcado pelo processo de democratização da sociedade, destacavam-se a ampliação quantitativa do acesso ao ensino fundamental e o fracasso escolar nessa modalidade de ensino. Autores como Fletcher e Ribeiro (1988) e Klein (2006) apresentam estudos que mostram que o acesso à primeira série do Ensino Fundamental envolvia aproximadamente $95 \%$ da população. Esses mesmos autores indicam que, porém, “cerca de $50 \%$ dos alunos matriculados no sistema regular de ensino repetem a primeira série a cada ano enquanto somente $2 \%$ se evadem" (KLein, 2006, P. 30). Esses dados são importantes porque podem auxiliar na superação do mito, ainda muito presente na área de educação, de que "a escola de antigamente ensinava mais e melhor" e que, portanto, os "métodos de antigamente" é que eram bons.

No entanto, como afirmam Klein e Fontanive (1995, p. 30), indicadores dessa natureza, embora úteis para dar uma ideia da eficiência do sistema, não fornecem informações sobre a qualidade do ensino oferecido aos alunos. "Era preciso verificar, então, não só o nível de atendimento, mas também, a qualidade dos serviços essenciais oferecidos à maioria da população" (1995, p. 34).

Nesse contexto, a avaliação externa à escola foi implementada com o objetivo de possibilitar uma percepção mais ampla da realidade e de contribuir para que o MEC instituísse políticas de avaliação que, realmente, estivessem de acordo com as necessidades do sistema educacional. Dentro dessa concepção, em 1990, foi implantado, pelo Instituto Nacional de Estudos e Pesquisas Educacionais Anísio Teixeira - Inep, o Sistema Nacional de Avaliação da Educação Básica - Saeb, que avalia, a partir de uma amostra representativa de sujeitos e com uma amostragem matricial 
de itens, alunos da $4^{\mathrm{a}}$ e da $8^{\mathrm{a}}$ séries do Ensino Fundamental (respectivamente, $5^{\circ}$ e $9^{\circ}$ anos de escolaridade, para as redes de ensino que já ampliaram o Ensino Fundamental para 9 anos) e do $3^{\circ}$ ano do Ensino Médio, em Língua Portuguesa e Matemática. Em 2005, visando à obtenção de dados mais detalhados da realidade educacional, foi instituída a Prova Brasil, que tem como objetivo avaliar censitariamente também, em Língua Portuguesa e Matemática, alunos da $4^{\mathrm{a}} \mathrm{e}$ da $8^{\text {a }}$ séries do Ensino Fundamental.

Avaliações atuais, como o próprio Saeb e a Prova Brasil, são concebidas para procurar responder a questões como: Foi ensinado e foi aprendido aquilo que deveria ter sido ensinado e aprendido?; O que foi ensinado corresponde a uma concepção atualizada dos conteúdos avaliados? Assim, em princípio, a avaliação externa à escola é concebida hoje para ser colocada a serviço da sociedade, visando disponibilizar subsídios para que a escola ensine aquilo que é necessário ensinar.

\section{QUESTÕES DA PESQUISA RELACIONADAS À AVALIAÇÃO DA ALFABETIZAÇÃO, LEITURA E ESCRITA}

Ao longo dos últimos anos, se configuram, de modo cada vez mais expressivo, demandas em torno da avaliação da alfabetização, leitura e escrita, sobretudo nos primeiros anos de escolarização. Essas demandas podem ser compreendidas a partir de, pelo menos, três aspectos fundamentais:

1. os resultados do Saeb, que apontam baixos índices de habilidades dos examinandos em leitura na $4^{\mathrm{a}}$ e $8^{\mathrm{a}}$ séries;

2. a meta estabelecida pelo governo federal de toda criança estar lendo e escrevendo aos oito anos de idade;

3. a expectativa, social e historicamente constituída, em torno do domínio da leitura e da escrita como uma das funções precípuas da escola - expectativa não concretizada para grande parte dos alunos das escolas públicas.

A fim de subsidiar a identificação de níveis de alfabetização, o Inep instituiu uma nova modalidade de avaliação externa à escola, a Provinha Brasil, que pressupõe a adesão voluntária 
de estados e municípios e visa propiciar o acesso a dados sobre alfabetização, leitura e escrita em momentos mais precoces da escolarização, quando há, em função do tempo, maiores possibilidades de intervenções. Essa avaliação apresenta, em seu desenho inicial, forte relação com a formação docente.

Paralelamente, em diferentes estados brasileiros, vem sendo instituídas experiências de avaliação da alfabetização em larga escala, que se configuram, ainda, como casos isolados e em fase de consolidação. É importante destacar que tais avaliações não têm incorporado dados de escrita ${ }^{2}$. A pesquisa aqui tratada foi motivada por essa realidade, propondo-se a tratar de questões como:

- Se e em que medida a aferição de níveis de alfabetização deve ser construída com base, apenas, em itens de leitura mesmo que haja, entre eles, itens que não têm como pressuposto um sujeito leitor?

- Que contribuições os itens de escrita (traduzidos a partir de escalas de proficiência) podem dar para a delimitação de padrões de desempenho na alfabetização?

- Que relações se podem estabelecer entre escalas de leitura e escrita?

- Que contribuições os dados de escrita infantil, obtidos a partir de testes padronizados, podem dar para a compreensão de padrões de desempenho dos alunos, quer do ponto de vista da metodologia utilizada nos testes, quer do ponto de vista do ensino na sala de aula?

Para oferecer respostas a tais questões, a pesquisa aqui abordada propõe realizar uma meta-análise de resultados de avaliações, o que é explicado na próxima seção.

\section{PROPOSTA DE CONSTRUÇÃO DE UM CORPUS DE ESCRITA INFANTIL}

A pesquisa enfocada propõe uma meta-análise de dados de avaliações. Mais especificamente, a proposta é a constituição de um corpus de escrita infantil, composto por itens de escrita da avaliação sistêmica e em larga escala, de caráter longitudinal, do estado do Espírito Santo, aplicada no $1^{\circ}, 2^{\circ}$ e $3^{\circ}$ anos do Ensino Fundamental, ao longo do período de 2008-2011: a
2 Nesse contexto, merece

destaque a Avaliação

Diagnóstica da Alfabetização no Estado do Espírito Santo -

Paebes Alfa - aqui focalizada

e a ser tratada adiante -

que avalia itens de escrita,

considerando-os em seus resultados. 
3 vale destacar que as avaliações do Paebes Alfa são desenvolvidas pelo Centr de Alfabetização, Leitura e Escrita - Ceale (da Faculdade de Educação - FaE da Universidade Federal de Minas Gerais - UFMG) em parceria com a Secretaria de Educação do Estado do Espírito Santo.
Avaliação Diagnóstica da Alfabetização no Estado do Espírito Santo - Paebes Alfa ${ }^{3}$. Vale destacar que os dados que comporão o corpus citado se referem às aplicações de 2010 e 2011.

A opção da pesquisa pela avaliação do estado do Espírito Santo se justifica por dois motivos principais: primeiro, por ser o único estado brasileiro que, neste momento, trabalha com avaliação censitária de caráter longitudinal que visa à identificação do valor agregado pela escola a partir da aplicação de avaliações de entrada no início do primeiro ano escolar; segundo, por também ser o único estado que tem, em sua escala de proficiência, itens de leitura e escrita.

Entende-se que a constituição de uma meta-análise dessa avaliação, com foco em itens de escrita, pode contribuir significativamente para a compreensão do papel de itens de escrita em avaliações externas à escola. Pode contribuir, também, para a reflexão acerca da possibilidade de constituição de novos desenhos de avaliações, especialmente em se tratando daquelas cujo foco é a alfabetização. Propõe-se, ainda, nessa metanálise, investigar a interação de competências e habilidades de leitura e de escrita, por meio da análise e produção de estudos sobre as escalas de proficiência de leitura e escrita.

A pesquisa tem, assim, como caráter inovador, a proposta de considerar a recente utilização de itens de escrita em uma avaliação externa à escola (BonAmino, BesSA, Franco, 2004). Outras avaliações dessa natureza como o Saeb e a Prova Brasil, de âmbito nacional e coordenadas pelo Inep, não contemplam itens de escrita. Mesmo no campo da pesquisa em avaliação externa, em que o GERES - Estudo Longitudinal da Geração Escolar 2005 (Oliveira, Franco e SOARES, 2007) traz grandes contribuições para uma maior compreensão desse tipo de avaliação, a aquisição da escrita no processo de alfabetização não é abordada.

Para além disso, há uma lacuna, no Brasil, de dados representativos de um corpus de escrita infantil. No que se refere a dados de avaliação externa, essa lacuna é ainda maior. Não se tem conhecimento de estudos dessa natureza que tenham como fonte primária itens de prova. Nesse aspecto, há de se destacar a urgência de se realizarem metanálises de caráter interdisciplinar de dados oriundos de avaliação, para fins de pesquisas que fomentem estudos sobre escrita infantil bem 
como estudos e construtos existentes no país sobre construção de escalas de proficiência. Se, por um lado, a exploração desses dados é embrionária, por outro, a avaliação oferece uma riqueza em termos de amplitude de dados e de refinamento metodológico na coleta.

Assim, além de contribuir para a elaboração de escalas de proficiência de leitura e de escrita, a pesquisa possibilita a constituição de um corpus de vocabulário infantil escrito, a partir de dados de escrita de palavras, frases e pequenos textos de uma avaliação externa. Vale destacar, ainda, que o estudo em foco inaugura a pesquisa de corpus com dados relacionados à apropriação de habilidades de uso da página pelo aprendiz da escrita, também a partir de dados de avaliação externa, no caso, os dados do Paebes Alfa.

\section{UMA ANÁLISE PRELIMINAR}

Análises estatístico-pedagógicas de dados de avaliações externas à escola no campo da alfabetização têm indicado níveis de aprendizagem de leitura e, mais recentemente, de escrita, que necessitam ser validados em estudos mais acurados. Isso seria importante para, por meio da construção de escalas de proficiência de escrita e de sua interlocução com escalas de leitura, investigar relações entre competências/habilidades de leitura e escrita no processo de alfabetização e aprendizagem da leitura e da escrita.

Neste trabalho, destacamos os resultados de uma análise preliminar de dados da avaliação em foco, o Paebes Alfa, nas suas duas edições (entrada e saída) de 2008. Na análise, foram considerados três tipos de itens: um de escrita de palavra; outro de escrita de frase ditada; e um último de escrita de frase referenciada em uma cena.

Um resultado interessante foi o de que os três itens aparecerem em pontos distintos da escala de proficiência, sendo que: o item de escrita de palavra aparece primeiro na escala, com uma menor proficiência; o item de escrita de frase referenciada em uma cena aparece em segundo lugar na escala, com uma proficiência intermediária; e o item de escrita de frase ditada aparece em terceiro lugar, com uma proficiência maior. 
Esse resultado é interessante por demonstrar que, se, por um lado, escrever palavra é mais fácil do que escrever frase, por outro, há diferenças entre escrever uma frase ditada e uma frase referenciada por uma cena: a frase ditada é um desafio maior para o aluno, porque ela determina as palavras que ele deve escrever. Ao contrário, o aprendiz tem maior facilidade de escrever frase referenciada por uma cena, que é uma situação de escrita mais espontânea, em que ele pode selecionar as palavras que irá escrever, evitando palavras que desconhece. Esse achado traz uma relevante reflexão para o professor alfabetizador. É importante que ele esteja atento aos diferentes desempenhos dos alunos nessas duas situações de escrita de frase, promovendo intervenções distintas para cada situação.

Outro resultado dessa análise preliminar com dados do Paebes Alfa (2008) que vale ser destacado é o de que, em cada um dos três tipos de itens de escrita citados, os itens aparecem em pontos diferentes da escala de proficiência. Assim, tomando como exemplo o item de escrita da palavra barco, na primeira ocorrência do item na escala, o aluno escreve tal palavra com omissões, acréscimos ou troca de letras, de modo que é muito difícil entender o que ele escreveu. Na segunda, ele escreve com erros ortográficos, mas já é possível entender o que escreveu. Na terceira e última ocorrência é que o aluno escreve tal palavra sem erros ortográficos. Situação semelhante ocorre com os outros itens de escrita. Isso indica, por um lado, a potencialidade dos itens de escrita (de caráter politômico) na apreensão de níveis de aprendizagem. Indica, por outro lado, que a aquisição de habilidades de escrita ocorre de forma gradual, definindo diferentes perfis de escritores.

\section{ASPECTOS METODOLÓGICOS DA PESQUISA}

A meta-análise dos itens de escrita das avaliações do Paebes Alfa proposta pela pesquisa ocorrerá a partir da constituição e análise estatístico-pedagógica de um corpus de itens que avalia habilidades de: 1) uso da página; 2) escrita de palavras; 3) escrita de frases (ditadas e escritas a partir de uma cena); e 4) escrita de textos. Com tal corpus, podem-se investigar aspectos da aquisição da escrita como os percursos empreendidos pelos 
alunos em relação à escrita de palavras e o domínio de habilidades de uso da página.

O corpus proposto pela pesquisa pretende contribuir tanto para as reflexões acerca da avaliação da alfabetização, leitura e escrita, notadamente no que concerne à potencialidade dos itens de escrita, quanto para a área de pesquisa de corpora de escrita infantil, ainda incipiente em nosso país (REscki, 2005). Merece destaque, nessa área, um corpus brasileiro denominado Projeto Laboratório Eletrônico de Oralidade e Escrita - e-Labore (Cristofaro-Silva, 2007). Contudo, o corpus do e-Labore, diferentemente do corpus proposto na pesquisa aqui abordada - o qual é composto por dados de escrita infantil coletados em situação de uma avaliação externa -, é constituído de escrita infantil realizada em situação de ensino/aprendizagem em sala de aula: redações de alunos de $1^{\circ}$ ao $7^{\circ}$ anos do ensino fundamental de 9 anos.

A pesquisa tratada neste trabalho tem como especificidade o fato de estruturar dados referentes à escrita de crianças, tanto no que diz respeito ao desenvolvimento de habilidades de uso da página quanto ao vocabulário infantil, contemplando um importante aspecto relacionado à pesquisa de corpora: o fator frequência da palavra (ByBEe, 2001; BoD, HAY, JANNEDY, 2001).

Em pesquisas de corpora, a noção de frequência auxilia a compreender diversos fenômenos de linguagem (Pinheiro, 1996). Vale mencionar os dois tipos de frequência apontados por Bybee (2001), os quais poderão ser pesquisados no corpus proposto pela pesquisa:

- frequência de ocorrência (token frequency): refere-se a quantas vezes uma unidade, geralmente uma palavra, ocorre em um corpus oral ou escrito. Um exemplo seria a pesquisa de uma palavra qualquer, como casa, no corpus proposto neste projeto. Pode-se investigar a frequência de ocorrência de tal palavra no corpus, ou seja, quantas vezes ela ocorreu nele.

- frequência de tipo (type frequency): refere-se à frequência de dicionário de um padrão particular. Um exemplo de pesquisa de frequência de tipo seria investigar quantas vezes o padrão encontro consonantal PR, por exemplo, ocorre no corpus, ou seja, em quantas palavras/ocorrências tal encontro consonantal ocorre. 
Em relação à coleta dos dados, o próprio rigor metodológico empregado em uma avaliação externa à escola, de grande porte, como o Paebes Alfa, garante que a obtenção de um amplo conjunto de dados seja feita com a utilização dos mesmos critérios, estratégias e até dos mesmos suportes de escrita. Além disso, permite que os dados sejam obtidos transversal e longitudinalmente em intervalos de tempo regulares.

Essas particularidades na coleta conferem maior fidedignidade aos dados obtidos, uma vez que fatores inerentes à sala de aula como a interferência do professor ou de colegas mais experientes são altamente minimizados.

Sobre o caráter longitundinal do Paebes Alfa, vale ressaltar que, em seu primeiro ano, 2008, tal programa de avaliação foi aplicado junto a alunos de $1^{\circ}$ e $2^{\circ}$ anos tanto no início ( $1^{\mathrm{a}}$ onda de aplicação/entrada) quanto no final ( $2^{\mathrm{a}}$ onda de aplicação/saída) do período letivo. Esses mesmos sujeitos foram avaliados na saída de 2009 ( $3^{\mathrm{a}}$ onda de aplicação) quando estavam no $2^{\circ}$ e $3^{\circ}$ anos de escolaridade. Paralelamente, foram avaliados, na entrada de 2009, os alunos que ingressaram no $1^{\circ}$ ano. Essa metodologia foi utilizada no ano de 2010 e está sendo aplicada neste ano de execução do Paebes Alfa. Como se destacou, os dados que comporão o corpus aqui tratado se referem às quatro aplicações de 2010 e 2011.

Ao final desses dois anos, esse programa de avaliação contará com o envolvimento de cerca de 400.000 alunos. Estima-se que, a partir das aplicações de 2010 e 2011, o total de itens de escrita que constituirá o corpus da pesquisa aqui tratada seja em torno de 1 milhão de itens, o que resultará em um número expressivo de dados de escrita para o corpus.

Em síntese, com a pesquisa aqui tratada, espera-se constituir um corpus de escrita infantil a partir de dados das avaliações do Paebes Alfa, os quais permitam, entre outras possibilidades:

- identificar e validar padrões de desempenho em escrita, e em leitura e escrita concomitantemente, propondo-se escalas de proficiência de leitura e escrita;

- investigar possíveis interações de competências e habilidades de leitura e escrita;

- compor um banco de dados com itens de leitura e escrita das avaliações citadas; 
- preservar a amostragem dos dados de escrita com sua configuração original, em formato eletrônico, por meio de sua digitalização e digitação (ver, no Apêndice I, as regras de digitação a serem consideradas na pesquisa);

- categorizar/codificar os dados de escrita, a partir das chaves utilizadas para a correção dos itens de escrita das avaliações (ver, no Apêndice II, chaves de correção referentes às habilidades de uso da página e de escrita de palavras);

- criar recursos de pesquisa/busca avançada em dados do corpus, a partir da digitação das produções escritas espontâneas das crianças como no original, com a apresentação do erro ortográfico e sua forma padrão correspondente.

\section{CONSIDERAÇÕES FINAIS}

Este trabalho tratou da pesquisa "Meta-avaliação da alfabetização: uma investigação do papel e potencialidade de itens e escalas de escrita", que propõe a constituição de um corpus de escrita infantil, composto de dados de uma avaliação em larga escala, na área de alfabetização, leitura e escrita: a Avaliação Diagnóstica da Alfabetização no Estado do Espírito Santo Paebes Alfa.

A pesquisa tratada neste trabalho tem como expectativa que a constituição do corpus de escrita infantil e a produção de escalas de proficiência que focalizem a escrita e suas interlocuções com escalas de leitura possibilitem novos estudos que contribuam para análises pedagógicas de dados de leitura e de escrita, oriundos de projetos de avaliações externas à escola.

Destaca-se que, entre as possíveis pesquisas a serem desenvolvidas a partir do corpus, evidenciam-se estudos sobre:

- os percursos da criança no processo de apropriação de habilidades de uso da página, o domínio da "estética" da escrita (orientação da escrita na página: da esquerda para a direita, de cima para baixo; uso da linha tanto no seu início quanto no final; mudança de linha etc.);

- a aquisição de padrões segmentais, silábicos e acentuais na escrita das crianças avaliadas pelo Paebes Alfa no $1^{\circ}$, $2^{\circ}$ e $3^{\circ}$ anos de escolarização do ensino fundamental; 
- o processo de aquisição da segmentação de palavras nos textos dessas crianças.

Espera-se, com a constituição do corpus e as pesquisas dele decorrentes, auxiliar em um processo de retroalimentação da avaliação, em que essas pesquisas são subsidiadas por dados da avaliação e também em que a avaliação, tanto no momento de sua elaboração quanto no de análise de seus dados, é subsidiada pelas pesquisas decorrentes do corpus.

\section{REFERÊNCIAS BIBLIOGRÁFICAS}

BOD, R.; HAY, J.; JANNEDY, S. Probabilistic Linguistics. MIT Press, 2004.

BONAMINO, Alicia; BESSA, Nicia; FRANCO, Creso. (Org.). Avaliação da Educação Básica. São Paulo: Loyola; Rio de Janeiro: Editora PUC Rio, 2004.

BYBEE, J. B. Phonology and Language Use. Cambridge: Cambridge University Press, 2001.

CRISTOFARO-SILVA, T. et al. Alfabetização e conhecimento linguístico: o Projeto e-Labore. In: LARA, Glaucia; COHEN, Maria Antonieta. (Org.). Linguística, tradução, discurso. 1 ed. Belo Horizonte: Editora da FALE, 2007, v. 1, p. 140-154.

FLETCHER, Philip R.; RIBEIRO, Sérgio Costa. 0 Ensino de $1^{\circ}$ grau no Brasil hoje. Em Aberto, Brasília, DF, n. 6, Inep/MEC, p. 1-4, 1988.

KLEIN, Ruben. Como está a educação no Brasil? O Que fazer? Ensaio, Rio de Janeiro, v. 14, n. 51, p. 139-172, abr.|jun. 2006.

KLEIN, Ruben; FONTANIVE, Nilma Santos. Avaliação em Larga Escala: uma proposta inovadora. Em aberto, Brasília, v. 15, n. 66, p. 29-34, abr.jjun.1995.

OLIVEIRA, Lina Katia; FRANCO, Creso; SOARES, Tufi Machado. Projeto Geres/2005: novos indicadores para construção e interpretação da escala de proficiência. Revista Eletrônica Iberoamericaba sobre Calidad, Eficácia y Cambio em Educación, v. 5, n. 2, p. 154-182, 2007.

PINHEIRO, A. Contagem de frequência de ocorrência de palavras expostas a crianças na faixa pré-escolar e séries iniciais do $1^{\circ}$ grau. Boletim da Associação Brasileira de Dislexia, p. 3-20, 1996.

PROJETO e-Labore. Corpus de linguagem infantil. Disponível em: <http://www.projetoaspa.org/elabore/index.php>. Acesso em: 5 abr. 2011.

RESCKI, L. Utilizando corpora de aprendizes para a investigação de aspectos discursivos, metodologias de ensino e design de materiais pedagógicos. Linguagem e Ensino. v. 8, n. 2, p. 249-273, 2005. 


\section{GLADYS ROCHA}

Professora da Faculdade de Educação da Universidade Federal de Minas Gerais, Pesquisadora do Centro de Alfabetização, Leitura e Escrita da Faculdade de Educação da Universidade Federal de Minas Gerais (Ceale/FaE/UFMG)

gladysrocha1@gmail.com

\section{RAQUEL FONTES MARTINS}

Professora da área de Letras da Universidade Federal de Lavras, Pesquisadora do Centro de Alfabetização, Leitura e Escrita da Faculdade de Educação da Universidade Federal de Minas Gerais (Ceale/FaE/UFMG) raquelfontesmartins@gmail.com 


\section{APÊNDICE 1}

\section{REGRAS DE DIGITAÇÃO}

Abaixo, seguem as sete regras de digitação aqui consideradas, com exemplos de trechos originais de escrita infantil e suas respectivas formas de digitação.

\section{REGRAS DE DIGITAÇÃO DE ITENS DE ESCRITA}

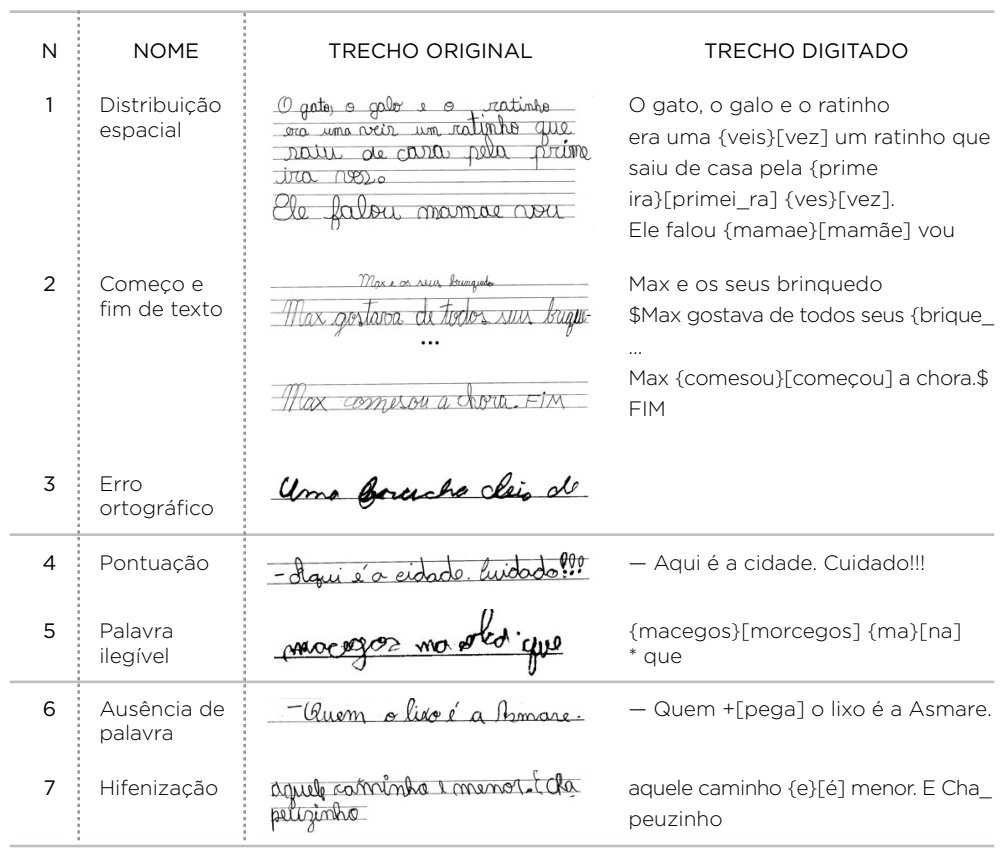

Fonte: Projeto E-labore (2011).

\section{APÊNDICE 2}

\section{CHAVES DE CORREÇÃO}

1. Chave de correção referente às habilidades de uso da página, utilizada nas avaliações do Paebes Alfa.

\section{USO ADEQUADO DA PÁGINA}

ATENÇ̃̃O: ortografia, pontuação, uso de letra maiúscula e segmentação de palavras NÃO devem ser considerados neste item. $\bigcirc$ foco desse item são as habilidades de uso da página (direções e alinhamento da escrita)

A Escreveu a frase usando a folha de forma adequada, seguindo todas as regras de uso da página: respeitando as direções da escrita (de cima para baixo e da esquerda para a direita), margens, linha e sequência da escrita - mudança de linha. OBSERVAÇÃo: 0 aluno pode ter escrito no início da 1aㅡ ou da 2a linha. 


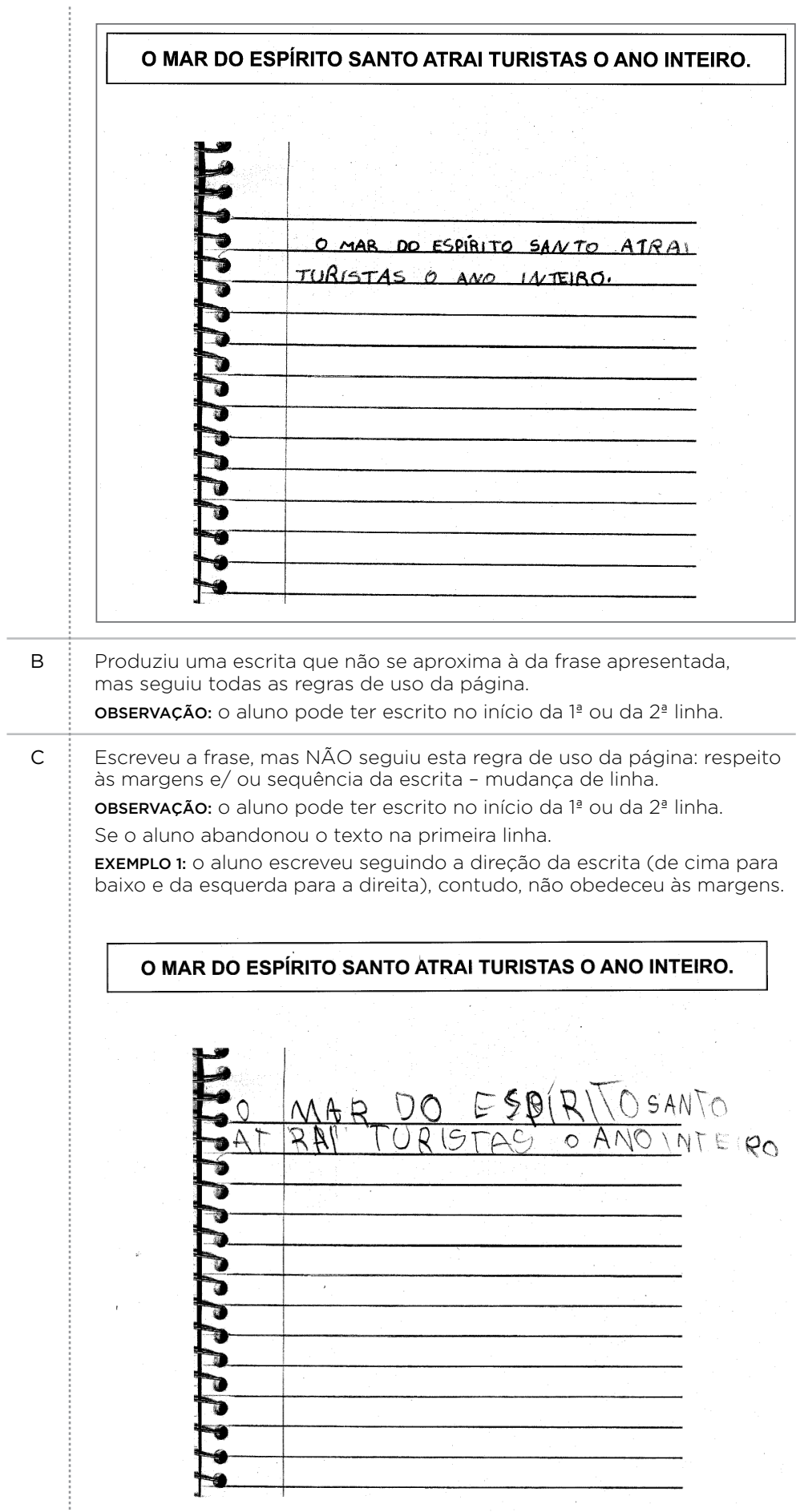


EXEMPLO 2: O aluno escreveu seguindo a direção da escrita (de cima para baixo e da esquerda para a direita) na 1ํㅣ linha, obedeceu às margens, contudo, não mudou de linha corretamente, retornando à margem esquerda na $2^{\text {a }}$ linha.

\section{O MAR DO ESPÍRITO SANTO ATRAI TURISTAS O ANO INTEIRO.}

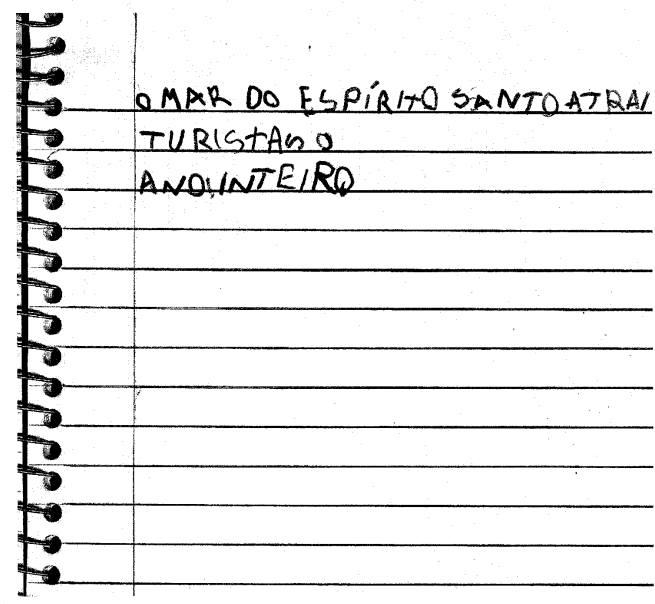

Ou se seguiu a direção da escrita, mas há ocorrências significativas de escrita no meio da linha. desrespeitou as direções da escrita (de cima para baixo e da esquerda para a direita) e não obedeceu às margens e à sequência da escrita mudança de linha.

E, ainda, se escrever a partir da terceira linha. EXEMPLO 1: o aluno escreveu desrespeitando a direção da escrita (especialmente a direção da esquerda para a direita), não obedecendo às margens (em especial, não começou a escrever no início da margem esquerda) e nem mudando de linha corretamente.

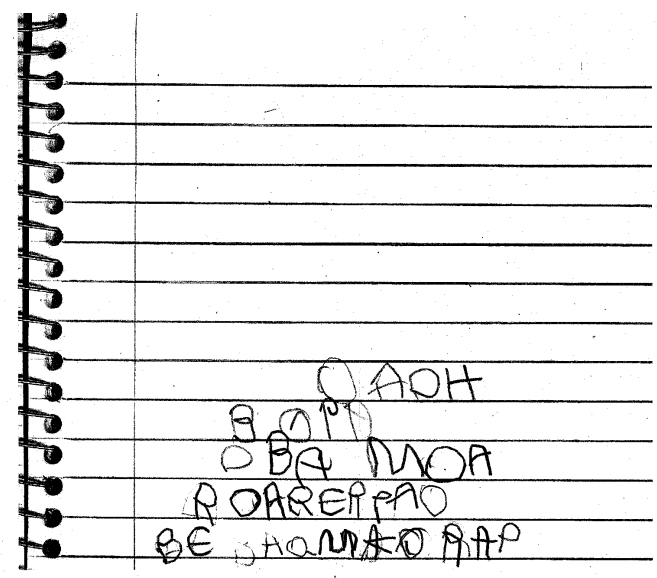


EXEMPLO 2: o aluno escreveu desrespeitando as direções da escrita (de cima para baixo e da esquerda para a direita), não obedecendo às margens (em especial, ultrapassou as margens) e nem mudando de linha corretamente.

O MAR DO ESPÍRITO SANTO ATRAI TURISTAS O ANO INTEIRO.

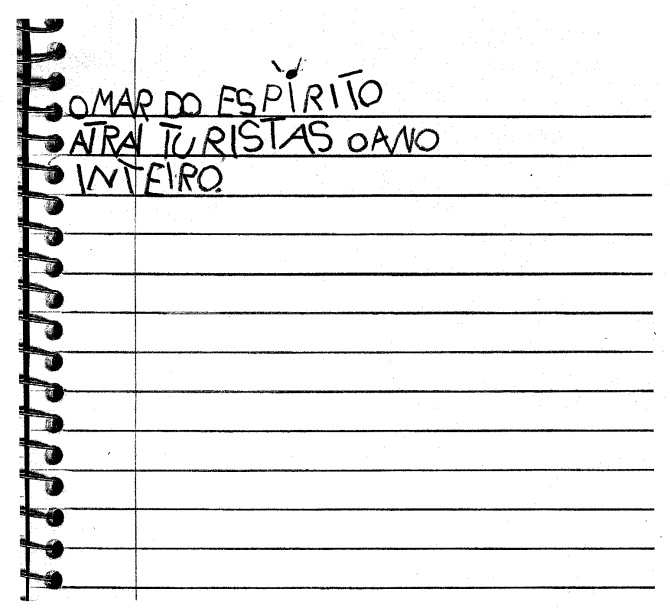

Produziu uma escrita que não se aproxima à da frase apresentada e também NÃO seguiu alguma(s) ou todas as regras de uso da página. Ainda, fez um desenho, um rabisco qualquer ou deixou a página em branco.

2. Chave de correção referente às habilidades de escrita de palavras, utilizada nas avaliações do Paebes Alfa.

\section{ESCRITA DE PALAVRA COM OU SEM APOIO DE IMAGEM}

A A palavra foi escrita corretamente (escrita ortográfica).

Nos itens com imagens, caso a palavra escrita não coincida com a palavra ditada, só será válida a resposta se houver estreita relação com a imagem.

B A palavra foi escrita com um erro, que pode ser: ortográfico (uma troca de letra; ou uma omissão de letra - caso dos dígrafos rr ss, nh...; ou um acréscimo de letra) ou hipersegmentação ou uma letra de forma espelhada.

Os tipos de erros mais comuns nesta categoria são, por exemplo, aqueles relacionados à semelhança articulatória dos sons que as letras representam ( $\mathrm{P} / \mathrm{B}, \mathrm{T} / \mathrm{D} /, \mathrm{C} / \mathrm{G}, \mathrm{F} / \mathrm{V}$...) ou à semelhança de traçado de certas letras (b/d, $\mathrm{q} / \mathrm{g} \ldots)$.

ATENÇÃo: $\bigcirc$ erro não pode comprometer a compreensão da palavra, formando nova palavra ou uma palavra inexistente que não pode ser associada ao significado daquele vocábulo cuja escrita foi solicitada. 
C A palavra foi escrita de modo alfabético, com 2 erros, que podem ser: ortográficos [troca, omissão ou acréscimo de letra(s)].

- hipersegmentação ou letra de forma espelhada.

Ainda assim é possível compreender a escrita sem maior cooperação

Os tipos de erros mais comuns nesta categoria são, por exemplo, aqueles relacionados à semelhança articulatória dos sons que as letras representam (P/B, T/D/, C/G, F/V...) ou à semelhança de traçado de certas letras $(b / d, a / g \ldots)$.

D A palavra foi escrita com três ou mais erros, que podem ser:

- ortográficos (troca, omissão ou acréscimo de letra(s));

- escrita de modo silábico-alfabético (ora com uma letra representando uma sílaba, ora com uma letra representando um som) ou silábico (com uma letra representando uma sílaba).

- de forma que compromete a leitura, não sendo possivel a

compreensão sem conhecer a palavra ditada, contudo a escrita

produzida pelo aluno apresenta relação com os sons da palavra, ou seja, com a pauta sonora.

O aluno escreveu:

- letras aleatórias para representar a palavra;

- utilizou desenhos ou garatujas;

- não escreveu a palavra. 